\title{
Insulin Secretory Abnormalities in Subjects with Hyperglycemia Due to Glucokinase Mutations
}

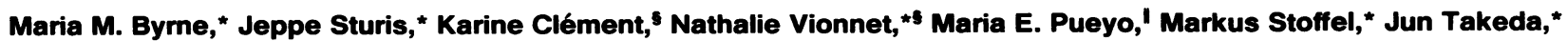 \\ Philippe Passa," Daniel Cohen, Graeme I. Bell, ${ }^{\star *}$ Gilberto Velho," Philippe Froguel," and Kenneth S. Polonsky* \\ Departments of ${ }^{*}$ Medicine and Biochemistry and Molecular Biology, and ${ }^{\ddagger}$ Howard Hughes Medical Institute, ${ }^{\ddagger}$ Pritzker School of \\ Medicine, The University of Chicago, Chicago, Illinois 60637; 'Centre d'Etude du Polymorphisme Humain (Foundation Jean Dausset), \\ 75010 Paris, France; and 'INSERM 358, Hopital Saint Louis, 75010 Paris, France
}

\section{Abstract}

Pancreatic $\beta$-cell function was studied in six subjects with mutations in the enzyme glucokinase (GCK) who were found to have elevated fasting and postprandial glucose levels in comparison to six normoglycemic controls. Insulin secretion rates (ISRs) were estimated by deconvolution of peripheral C-peptide values using a two-compartment model and individual $\mathrm{C}$ peptide kinetics obtained after bolus intravenous injections of biosynthetic human C-peptide. First-phase insulin secretory responses to intravenous glucose and insulin secretion rates over a 24-h period on a weight maintenance diet were not different in subjects with GCK mutations and controls. However, the dose-response curve relating glucose and ISR obtained during graded intravenous glucose infusions was shifted to the right in the subjects with GCK mutations and average ISRs over a glucose range between 5 and $9 \mathrm{mM}$ were $61 \%$ lower than those in controls. In the controls, the $\beta$ cell was most sensitive to an increase in glucose at concentrations between 5.5 and $6.0 \mathrm{mM}$, whereas in the patients with GCK mutations the point of maximal responsiveness was increased to between 6.5 and $7.5 \mathrm{mM}$. Even mutations that resulted in mild impairment of in vitro enzyme activity were associated with a $>\mathbf{5 0} \%$ reduction in ISR. The responsiveness of the $\beta$ cell to glucose was increased by $45 \%$ in the subjects with mutations after a $42-h$ intravenous glucose infusion at a rate of 4-6 $\mathrm{mg} / \mathrm{kg}$ per min. During oscillatory glucose infusion with a period of $144 \mathrm{~min}$, profiles from the subjects with mutations revealed reduced spectral power at 144 min for glucose and ISR compared with controls, indicating decreased ability to entrain the $\beta$ cell with exogenous glucose. In conclusion, subjects with mutations in GCK demonstrate decreased responsiveness of the $\beta$ cell to glucose manifest by a shift in the glucose ISR dose-response curve to the right and reduced ability to entrain the ultradian oscillations of insulin secretion with exogenous glucose. These results support a key role for the enzyme GCK in determining the in vivo glucose / ISR dose-response relationships and define the alterations in $\beta$-cell responsiveness that occur in subjects with GCK mutations. (J. Clin. Invest. 1994. 93:1120-1130.) Key words: gluco-

Address correspondence to Dr. Kenneth S. Polonsky, Department of Medicine, The University of Chicago, 5841 S. Maryland AvenueMC1027, Chicago, IL 60637.

Received for publication 3 June 1993 and in revised form 28 October 1993.

J. Clin. Invest.

(C) The American Society for Clinical Investigation, Inc.

$0021-9738 / 94 / 03 / 1120 / 11 \$ 2.00$

Volume 93, March 1994, 1120-1130 kinase mutations $\bullet$ impaired glucose tolerance $\bullet$ insulin secretion - maturity-onset diabetes of the young • non-insulin-dependent diabetes mellitus

\section{Introduction}

It has recently been determined that maturity-onset diabetes of the young, a form of non-insulin-dependent diabetes mellitus (NIDDM $)^{1}$ with an early age of onset and autosomal dominant inheritance, may result from mutations in glucokinase (GCK), the first rate-limiting enzyme in the metabolism of glucose by the pancreatic $\beta$ cell (1-6). Subjects with GCK mutations are usually characterized by mild fasting hyperglycemia (i.e., glucose levels $>6.1 \mathrm{mM}$ ), which is evident in childhood. First-phase insulin secretion after intravenous glucose administration has been reported to be normal in subjects with GCK mutations whereas responses to continuous glucose infusion were significantly reduced (5). On the basis of these findings, it has been suggested that GCK-deficient diabetes represents a form of NIDDM in which the primary defect resides in the $\beta$ cell although the potential role of liver GCK in the pathogenesis of this syndrome has not been defined. Detailed characterization of the $\beta$-cell dysfunction that occurs in these subjects should provide unique insights into the role of glucokinase in glucose sensing and in the regulation of insulin secretion. The $\beta$-cell responses in these subjects to stimuli other than intravenous glucose have not been reported nor have the effects of mutations in GCK on the glucose/insulin secretion dose-response relationships or on oscillatory insulin secretion patterns been studied. The present study was undertaken to address these issues and to define the clinical pathophysiology of alterations in $\beta$-cell function in subjects with GCK mutations.

\section{Methods}

\section{Subjects}

Studies were performed in four males and two females from kindreds with known GCK mutations and in six controls pair matched for age, weight, and sex. Clinical profiles of the subjects with GCK mutations and their controls are shown in Table I. Mean fasting glucose levels were significantly higher in the subjects with GCK mutations $(6.72 \pm 0.12$ vs. $5.04 \pm 0.17 \mathrm{mM}, P<0.0008)$, and they all had fasting glucose values $>6.1 \mathrm{mM}$ which is $2 \mathrm{SD}$ greater than the mean value in a matched nondiabetic French population (7). Glycosylated hemoglobin values (Glyc-Affin GHb kit, Isolab, Inc., Akron, $\mathrm{OH}$ ) were available in four of the six subjects with mutations (GK3, GK4, GK5, and GK6) and all were above $6.2 \%$ which is the upper limit of normal in

1. Abbreviations used in this paper: GCK, glucokinase; ISR, insulin secretion rate; NIDDM, non-insulin-dependent diabetes mellitus. 
Table I. Demographic and Clinical Data on Patients and Controls

\begin{tabular}{|c|c|c|c|c|c|c|c|}
\hline $\begin{array}{l}\text { Identification } \\
\text { no. }\end{array}$ & Sex & Age & BMI & $\begin{array}{l}\text { Fasting } \\
\text { glucose }\end{array}$ & $\begin{array}{c}\text { 2-h } \\
\text { glucose }\end{array}$ & $\begin{array}{l}\text { Fasting } \\
\text { insulin }\end{array}$ & $\begin{array}{l}\text { Glycosylated } \\
\text { hemoglobin }\end{array}$ \\
\hline & & $y r$ & $\mathrm{~kg} / \mathrm{m}^{2}$ & $m M$ & $m M$ & $p M$ & $\%$ \\
\hline GK2 & $\mathbf{M}$ & 18 & 19.1 & 7.2 & 11.2 & 41 & NA \\
\hline GK3 & $\mathrm{F}$ & 33 & 18.8 & 6.4 & 12.4 & 21 & 6.8 \\
\hline GK4 & $\mathbf{F}$ & 48 & 24.6 & 6.7 & 5.0 & 62 & 7.6 \\
\hline GK5 & $\mathbf{M}$ & 21 & 21.2 & 6.8 & 8.6 & 48 & 7.2 \\
\hline GK6 & $\mathbf{M}$ & 45 & 25.0 & 6.8 & 11.5 & 49 & 8.5 \\
\hline GK7 & $\mathbf{M}$ & 18 & 22.8 & 6.4 & 5.7 & 59 & NA \\
\hline Subjects & & $30.5 \pm 5.6$ & $22.0 \pm 1.1$ & $6.7 \pm 0.1^{*}$ & $9.1 \pm 1.3$ & $46.7 \pm 6.0$ & $7.5 \pm 0.4$ \\
\hline CK2 & $\mathbf{M}$ & 21 & 18.8 & 4.7 & 5.3 & 28 & NA \\
\hline CK3 & $\mathrm{F}$ & 29 & 21.9 & 5.3 & NA & 71 & NA \\
\hline CK4 & $\mathbf{F}$ & 48 & 25.1 & 4.3 & NA & 42 & NA \\
\hline CK5 & $\mathbf{M}$ & 19 & 21.9 & 4.9 & NA & 61 & NA \\
\hline CK6 & $\mathbf{M}$ & 39 & 27.9 & 5.3 & NA & 70 & NA \\
\hline CK7 & $\mathbf{M}$ & 18 & 19.2 & 5.4 & NA & 56 & NA \\
\hline Controls & & $29.0 \pm 5.0$ & $22.5 \pm 1.4$ & $5.0 \pm 0.2$ & NA & $54.7 \pm 6.9$ & $<6.2 \%$ \\
\hline
\end{tabular}

Patients are denoted GK; controls are denoted CK. NA, not available. The 2-h glucose values were obtained $2 \mathrm{~h}$ after ingestion of $75 \mathrm{~g}$ of glucose. ${ }^{*} P<0.0008$ vs. controls.

our assay. All participants were within $20 \%$ of ideal body weight. Use of the homeostasis model assessment method $(8)$ which utilizes fasting plasma glucose and insulin values showed no difference in relative insulin resistance between the two groups ( subjects, $2.0 \pm 0.3$; controls, $1.8 \pm 0.3 ; P>0.6)$. One of the controls $>\mathrm{CK} 2$ was a sibling of GK 2 and had no mutation. The remainder of the controls did not have a personal or family history of diabetes. Moreover, they had no medical illnesses nor were they receiving any medications. All subjects were placed on a weight maintenance diet containing at least $200 \mathrm{~g}$ of carbohydrate per day for 2 wk before study. Female volunteers had regular menstrual cycles and were studied only in the early follicular phase. Meal studies and intravenous glucose tolerance tests in the subjects with mutations were performed at the Diabetes and Endocrinology Department, Hôpital Saint Louis, Paris, France. All remaining studies were performed in the Clinical Research Center at the University of Chicago. The protocols were approved by the local institutional review boards and written informed consent was obtained.

\section{Experimental protocol}

Each subject participated in a series of studies that allowed C-peptide kinetics to be measured and the glucose, insulin, and C-peptide responses to various experimental protocols to be evaluated. All studies were performed after a 12-h overnight fast beginning at 0800 unless otherwise stated with subjects in the recumbent position. An intravenous catheter was placed in each forearm, one for blood sampling and one for administration of glucose or C-peptide as needed. In all experiments, the arm containing the sampling catheter was maintained in a heating blanket to ensure arterialization of the venous sample.

C-peptide kinetic studies. Individual C-peptide kinetic parameters were estimated in all 12 subjects as previously described (9). In brief, during suppression of endogenous $C$-peptide secretion by a primed intravenous infusion of somatostatin $(350 \mu \mathrm{g} / \mathrm{h}$; Bachem Fine Chemicals, Torrance, CA), a bolus injection of $150 \mu \mathrm{g}$ of biosynthetic human C-peptide (Eli Lilly and Co., Indianapolis, IN) was administered intravenously and plasma $C$-peptide levels were measured at frequent intervals for the next $3 \mathrm{~h}$. Individual $\mathrm{C}$-peptide kinetic parameters were determined by analysis of the $C$-peptide decay curves and these parameters were then used to derive insulin secretion rates by deconvolution of peripheral C-peptide concentrations assuming a two-compartment model of C-peptide distribution $(9,10)$.
Intravenous glucose tolerance tests. After obtaining baseline samples, $30 \%$ dextrose was injected intravenously over a period of $3 \mathrm{~min}$ (total dose of $500 \mathrm{mg} / \mathrm{kg}$ body weight). Blood samples for glucose, insulin, and C-peptide were obtained at 1,3,5, 10, 15, and 30 min after terminating the glucose injection.

24- $h$ profiles of glucose and insulin secretion rates. On a separate occasion, patients were studied over a 24 -h period on a weight maintenance diet consisting of $30 \mathrm{kcal} / \mathrm{kg}$ with $50 \%$ carbohydrate, $15 \%$ protein, and $35 \%$ fat. Total food intake was divided into three meals which were presented at 0900,1300 , and 1800 and were consumed within 20 min. $20 \%$ of calories were eaten at breakfast and $40 \%$ with lunch and dinner respectively. Blood sampling for glucose, insulin, and C-peptide began at 0600 after a 12 -h overnight fast and continued via an indwelling catheter at 20-min intervals for $24 \mathrm{~h}$.

Graded intravenous glucose infusion studies. These studies were designed to explore the dose-response relationships between glucose and insulin secretion rate (ISR). In order to eliminate potentially confounding effects of differences in the basal glucose concentration, each study began with the administration of a small bolus of insulin intravenously $(0.007 \mathrm{U} / \mathrm{kg})$ followed by a low-dose continuous infusion of insulin for $20 \mathrm{~min}$ in the subjects with GCK mutations, to lower the fasting plasma glucose to similar levels in both groups. The total dose of insulin administered was $1.84 \pm 0.16 \mathrm{U}$ in the patients vs. $0.46 \pm 0.03 \mathrm{U}$ in the controls. After a period of 20 min during which time the exogenously administered insulin was allowed to decay, samples were drawn at 10-min intervals for $30 \mathrm{~min}$ to define baseline insulin, glucose, and C-peptide levels. An intravenous infusion of $20 \%$ dextrose was then started at a rate of $1 \mathrm{mg} / \mathrm{kg}$ per min, followed by infusions of $2,3,4,6$, and $8 \mathrm{mg} / \mathrm{kg}$ per min. Each infusion rate was administered for a period of $40 \mathrm{~min}$. Insulin, C-peptide, and glucose concentrations were measured at 10,20,30, and 40 min into each glucose infusion period.

In order to document that the administration of insulin to lower the fasting glucose did not affect subsequent insulin secretory responses, three subjects were studied on two occasions. Insulin was administered before the graded glucose infusion protocol described above on one occasion and on the other occasion the insulin was omitted. Repeated measures analysis of variance revealed that administration of insulin caused no alterations in ISR in the physiological range of glucose levels between 5 and $9 \mathrm{mM}(257 \pm 143 \mathrm{pmol} / \mathrm{min}$ with insulin vs. $262 \pm 111$ $\mathrm{pmol} / \mathrm{min}$ without insulin, $P>0.7$ ). 
Effects of glucose administration on insulin secretory responses to graded glucose infusions. In order to determine if the insulin secretory responses to glucose were altered by glucose infusion, each graded glucose infusion study described above was followed by a 42-h glucose infusion at a rate of 4-6 mg/ $\mathrm{kg}$ per min. During the second day of this glucose infusion, subjects also consumed three carbohydrate-enriched meals. At the conclusion of the 42-h infusion period, the glucose infusion was reduced over a 60 -min period and then stopped. 30 min later, the graded glucose infusion was repeated. Mean glucose levels obtained during the 42-h glucose infusion were $9.7 \pm 0.2 \mathrm{mM}$ in the subjects with GCK mutations vs. $6.8 \pm 0.2 \mathrm{mM}(P<0.0002)$ in the controls.

Ultradian oscillations of insulin secretion. In order to study ultradian oscillations of insulin secretion in the two groups, glucose was infused in an oscillatory pattern for the first $16 \mathrm{~h}$ of the 42-h glucose infusion in four patients and their matched controls. The amplitude of these oscillations was $33 \%$ above and below the mean rate of $6 \mathrm{mg} / \mathrm{kg}$ per min and their periodicity was $144 \mathrm{~min}$. Blood samples for glucose, insulin, and C-peptide were drawn at 15-min intervals for the last $12 \mathrm{~h}$ of the oscillatory infusion (1800-0600).

Assays. Plasma glucose was measured by the glucose oxidase technique (analyzer, Yellow Springs Instrument Co., Yellow Springs, $\mathrm{OH}$ ). The coefficient of variation of this method is $<2 \%$. Serum insulin was assayed by a double-antibody assay (11) with a lower limit of sensitivity of $20 \mathrm{pM}$ and an average intraassay coefficient of variation of $6 \%$. Plasma C-peptide was measured as previously described (12). The lower limit of sensitivity of the assay is $0.02 \mathrm{pmol} / \mathrm{ml}$ and the intraassay coefficient of variation averaged $6 \%$. All samples were measured in duplicate. Assays were performed at the University of Chicago.

\section{Data analysis}

Estimation of ISRs. ISRs over each sampling interval were derived by deconvolution of endogenously secreted peripheral C-peptide concentrations using a two-compartment model of C-peptide kinetics and the individually derived $\mathrm{C}$-peptide kinetic parameters obtained by analysis of the C-peptide decay curves $(9,10)$ as described above.

Intravenous glucose tolerance tests. The first-phase insulin secretion rate response to glucose was calculated as the incremental area under the ISR curve from 0 to $10 \mathrm{~min}$ after terminating the intravenous glucose bolus. The corresponding areas under the curves for glucose were also calculated.

24-h profiles of glucose and insulin secretion. The fasting ISR ( $\mathrm{pmol} / \mathrm{min}$ ) was defined as the secretion rate during the period 0600 0900. The basal insulin secretion during the 24 -h period was deduced by extrapolating the fasting secretion rate during that period. The total amount of insulin secreted daily $(\mathrm{nmol})$ was calculated as the area under the 24-h profiles of instantaneous secretion rates. The insulin secretory response to each meal was calculated as the peak ISR during the 4-h period after each meal minus the ISR immediately before meal consumption. This difference was then expressed as a percentage of the premeal value. The incremental area under the curve was also calculated for each 4-h interval after breakfast, lunch, and dinner were served.

Relationships between glucose concentrations and ISRs. These relationships were explored by analyzing the data from the graded glucose infusion studies. Baseline glucose, insulin, C-peptide, and ISRs were calculated as the mean of the values in the $-30,-20,-10$, and 0 min samples. ISRs and glucose levels used in the analysis represented the average of the values between 10 and $40 \mathrm{~min}$ at each glucose infusion rate. Mean ISR for each glucose infusion rate was then plotted against the corresponding mean glucose level to define the dose-response relationship. Mean ISRs were determined for $1 \mathrm{mM}$ glucose concentration intervals by calculating the area under the curve for each interval using the trapezoidal rule. This area was divided by $1 \mathrm{mM}$ to obtain the correct units ( $\mathrm{pmol} / \mathrm{min}$ ). In order to determine if the ability of the $\beta$ cell to respond to a given increment in glucose differed at different glucose concentrations, corresponding individual glucose levels and ISRs were sorted in ascending order of the glucose concentration and a smooth dose-response curve was calculated using a four-point moving average. Mean ISRs were then calculated at $0.5 \mathrm{mM}$ glucose intervals for each individual study. The local absolute slope at a given glucose interval was defined as the increment in ISR from that interval to the next, divided by the glucose interval $(0.5 \mathrm{mM})$. This definition yields the units $\mathrm{pmol} /(\mathrm{min} \times \mathrm{mM})$. The local relative slope at a particular glucose interval was defined as the absolute slope expressed as a percentage of the mean ISR over the corresponding glucose interval $(\% / \mathrm{mM})$. The relative slope was interpreted as an index of $\beta$-cell responsiveness, because it measures the percent relative increment in ISR per millimolar increment in glucose concentration.

\section{Ultradian oscillations in insulin secretion}

Pulse analysis. Individual ISR and glucose profiles from the last $12 \mathrm{~h}$ of the oscillatory glucose infusion studies were analyzed using Ultra, a computer program for pulse identification (13). Peaks of insulin secretion in the time series were considered true secretory pulses if both the increment and the decrement exceeded three times the measurement error of the C-peptide assay. Previous studies have shown that such a detection limit results in a false-positive rate of $<1 \%$ and thus minimizes the impact of any cumulative error resulting from deconvolution (13). For each significant pulse, the absolute increment was defined as the difference between the level of ISR at the peak of secretion and the ISR at the preceding trough.

Spectral analysis. Each individual ISR and glucose profile from the oscillatory glucose infusion protocol was submitted to spectral analysis to investigate whether the oscillations were entrainable in the two groups (14). Each series was detrended with the first difference filter before spectral estimates were calculated with the window closing procedure using a Tukey window as described by Jenkins and Watts (14).

\section{Statistical analyses}

All results are expressed as mean \pm SEM. Data analysis was performed using the Statistical Analysis System (SAS Version 6 Edition for Personal Computers; SAS Institute, Inc., Cary, NC). The significance of differences between the groups was determined using the paired $t$ test or analysis of variance where appropriate. Nonlinear least squares regression analysis of the C-peptide decay curves was performed using the BMDP 3R program (BMDP Statistical Software, Los Angeles, CA).

\section{Results}

\section{C-peptide kinetic parameters}

The average kinetic parameters in the subjects with GCK mutations were $3,145 \pm 199 \mathrm{ml}$ for the volume of distribution, $0.064 \pm 0.011 \mathrm{~min}^{-1}$ for $K_{1}, 0.051 \pm 0.006 \mathrm{~min}^{-1}$ for $K_{2}$, and $0.071 \pm 0.006 \mathrm{~min}^{-1}$ for $K_{3}$. Corresponding values in the controls were $3,633 \pm 384 \mathrm{ml}$, and $0.060 \pm 0.007,0.047 \pm 0.002$, and $0.065 \pm 0.004 \mathrm{~min}^{-1}$, respectively. Group differences were not statistically significant by multivariate analysis of variance $(P$ $>0.76$ ).

\section{Intravenous glucose tolerance tests}

The area under the curve for glucose from 0 to $10 \mathrm{~min}$ was $200 \pm 8 \mathrm{mM} \times \min$ in the patients vs. $157 \pm 11 \mathrm{mM} \times \min$ in the controls $(P<0.005)$. The corresponding areas under the curves for ISR and insulin were not significantly different between the two groups. In Table II, the individual areas under the curve for 0-10 min are for each subject listed for glucose, ISR, and insulin.

\section{4- $h$ meal studies}

Fasting and 24-h levels of insulin, ISR, and glucose. Mean profiles of plasma glucose, insulin, and ISR during the 24-h study are shown in Fig. 1. Plasma glucose levels were significantly higher in the subjects with GCK mutations both under 


\begin{tabular}{|c|c|c|c|c|c|c|c|c|}
\hline \multirow{2}{*}{$\begin{array}{c}\text { Identification } \\
\text { subject (control) }\end{array}$} & \multicolumn{3}{|c|}{$\begin{array}{l}\text { Area under the curve from } 0 \text { to } 10 \mathrm{~min} \text { during } \\
\text { intravenous glucose tolerance test }\end{array}$} & \multicolumn{3}{|c|}{ 24-h means from meal studies } & \multicolumn{2}{|c|}{$\begin{array}{l}\text { Mean levels from } 5 \text { to } \\
9 \mathrm{mM} \text { glucose } \\
\text { during baseline graded } \\
\text { glucose infusion study }\end{array}$} \\
\hline & Glucose & ISR & Insulin & Glucose & ISR & Insulin & ISR & Insulin \\
\hline & $m M \times \min$ & nmol & $n m o l \times \min \operatorname{per} L$ & $m M$ & $\mathrm{pmol} / \mathrm{min}$ & $p M$ & $\mathrm{pmol} / \mathrm{min}$ & $p M$ \\
\hline GK2 (CK2) & $171(148)$ & $4.6(8.1)$ & $1.6(1.3)$ & $7.9(5.4)$ & 99 (137) & $78(60)$ & $63(232)$ & $57(87)$ \\
\hline GK3 (CK3) & $186(116)$ & $5.3(2.6)$ & $1.5(1.9)$ & $7.7(5.1)$ & $83(107)$ & $74(105)$ & $61(134)$ & $38(138)$ \\
\hline GK4 (CK4) & $218(180)$ & $12.4(8.7)$ & $4.6(3.5)$ & $6.9(5.3)$ & $153(126)$ & $132(107)$ & $95(235)$ & $82(163)$ \\
\hline GK5 (CK5) & $213(141)$ & $13.6(9.8)$ & $4.6(6.3)$ & $7.4(5.3)$ & $176(167)$ & $129(184)$ & $114(320)$ & $63(198)$ \\
\hline GK6 (CK6) & $216(186)$ & $11.4(19.9)$ & $2.1(12.2)$ & $7.2(5.7)$ & $111(206)$ & $69(223)$ & $83(378)$ & $44(289)$ \\
\hline GK7 (CK7) & $197(172)$ & $11.8(10.2)$ & $3.8(2.7)$ & $6.6(5.9)$ & $147(157)$ & $117(125)$ & $132(211)$ & $80(110)$ \\
\hline Mean \pm SE & $\begin{array}{c}200 \pm 8 \\
(157 \pm 11)\end{array}$ & $\begin{array}{c}9.9 \pm 1.6 \\
(9.9 \pm 2.3)\end{array}$ & $\begin{array}{c}3.0 \pm 0.6 \\
(4.7 \pm 1.7)\end{array}$ & $\begin{array}{c}7.3 \pm 0.2 \\
(5.5 \pm 0.1)\end{array}$ & $\begin{array}{c}128 \pm 15 \\
(150 \pm 14)\end{array}$ & $\begin{array}{c}100 \pm 12 \\
(134 \pm 24)\end{array}$ & $\begin{array}{c}91 \pm 12 \\
(252 \pm 35)\end{array}$ & $\begin{array}{c}61 \pm 7 \\
(164 \pm 30)\end{array}$ \\
\hline $\begin{array}{l}\text { Level of } \\
\quad \text { significance }(\mathrm{P})\end{array}$ & $<0.005$ & $>0.98$ & $>0.39$ & $<0.002$ & $>0.26$ & $>0.25$ & $<0.006$ & $<0.03$ \\
\hline
\end{tabular}

fasting conditions ( $6.8 \pm 0.2$ vs. $5.1 \pm 0.2 \mathrm{mM}, P<0.004)$, and over the 24 -h period $(7.3 \pm 0.2$ vs. $5.5 \pm 0.1 \mathrm{mM}, P<0.002)$. Peak postprandial glucose levels did not increase $>10 \mathrm{mM}$ and glucose levels returned to fasting levels after each meal. Average basal ISRs did not differ between the patients and controls ( $77 \pm 15$ vs. $79 \pm 13 \mathrm{pmol} / \mathrm{min}, P>0.8$ ), nor did the total amount of insulin secreted over the $24-\mathrm{h}$ period ( $185 \pm 21$ vs. $216 \pm 21 \mathrm{nmol}, P>0.26)$. In the subjects with GCK mutations, basal insulin secretion represented $43 \%$ of the total 24 -h secretion, which was not significantly different $(P>0.3)$ from the percentage of basal insulin secretion of $47 \%$ observed in the control subjects. Individual $24-\mathrm{h}$ mean glucoses, ISRs, and insulins are listed in Table II. The incremental area under the insulin secretion response curve for the $4 \mathrm{~h}$ after breakfast was less in the subjects with GCK mutations than in their controls $(20.9 \pm 2.3$ vs. $29.9 \pm 2.6 \mathrm{nmol}, P<0.04)$, but there were no significant differences after lunch $(27.7 \pm 2.6$ vs. $38.2 \pm 4.6$ nmol, $P>0.11)$ and dinner $(28.1 \pm 2.6$ vs. $35.6 \pm 8.0 \mathrm{nmol}, P$
$>0.39)$. The peak ISR after each meal expressed as a percentage of the corresponding secretion rate for $1 \mathrm{~h}$ before the meal was significantly lower in the subjects with GCK mutations compared with that in controls after breakfast (395 $\pm 42 \%$ vs. $736 \pm 128 \%, P<0.01)$. There were no differences in the insulin secretory responses to lunch $(577 \pm 119 \%$ vs. $735 \pm 182 \%, P$ $>0.58)$ and dinner $(271 \pm 47 \%$ vs. $392 \pm 75 \%, P>0.25)$ between groups.

\section{Responses to graded intravenous glucose infusions}

Fasting plasma glucose levels were higher in the subjects with the GCK mutations compared with those in controls $(6.7 \pm 0.1$ vs. $5.0 \pm 0.2 \mathrm{mM}, P<0.0008)$ before the graded intravenous glucose infusion studies. After insulin administration plasma glucose concentrations were similar in both groups $(5.1 \pm 0.2$ vs. $4.7 \pm 0.2 \mathrm{mM}, P>0.15)$. Glucose, insulin, and ISR responses to the glucose infusions are shown in Fig. 2. Average glucose concentrations over the duration of the study were sig-
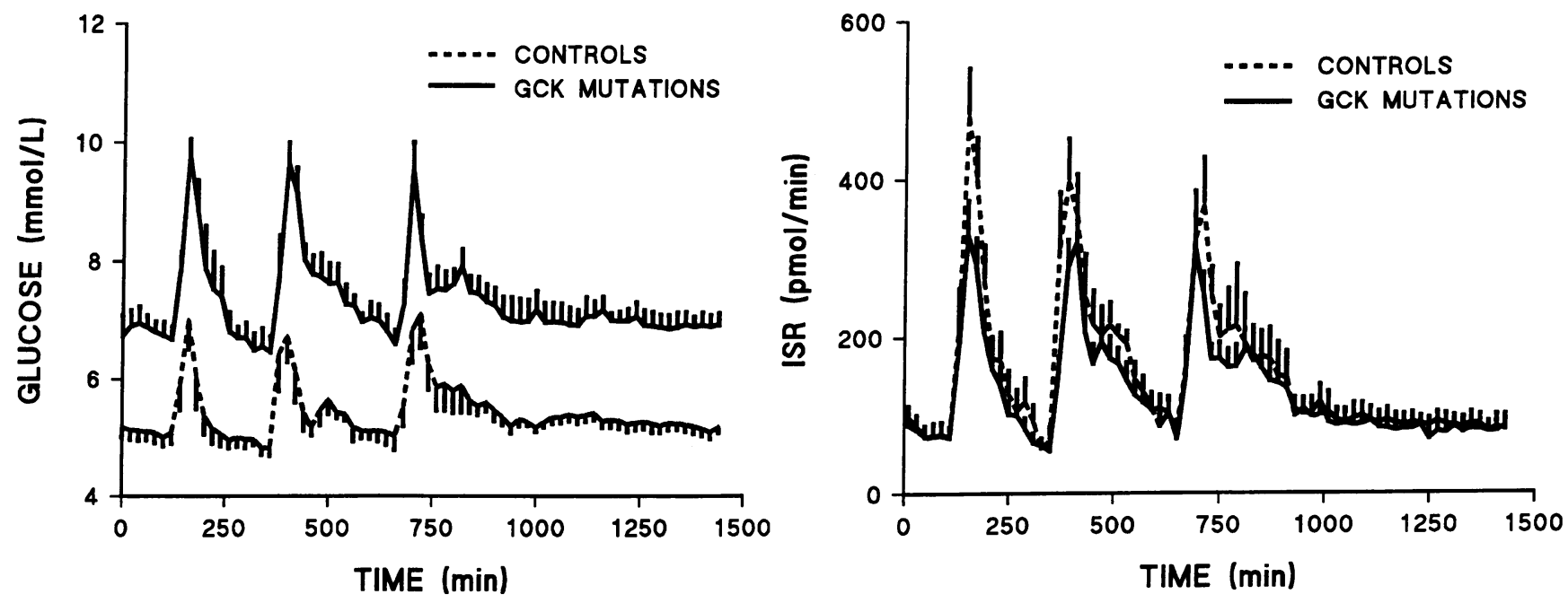

Figure 1. 24-h profiles of glucose and insulin secretion in a weight maintenance diet. Breakfast, lunch, and dinner were presented at 0900 , 1300 , and 1800 . 


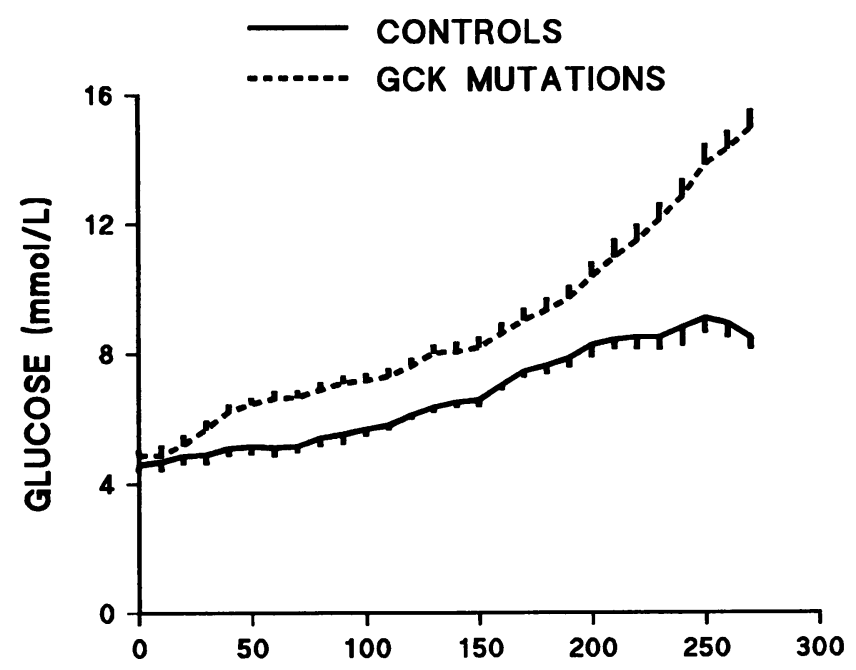

In order to allow the ISRs to be compared in the two groups at the same plasma glucose levels, the average amount of insulin secreted at each glucose infusion rate was plotted against the corresponding glucose level. The resulting glucose/ISR doseresponse relationships are shown in Fig. 3. In the controls, small increments in glucose resulted in large increments in the ISR particularly at glucose concentrations which are close to basal levels. In this group, on average $136 \pm 21$ pmol of insulin were secreted per minute at glucose levels between 5 and $6 \mathrm{mM}$ and this increased to $211 \pm 28 \mathrm{pmol} / \mathrm{min}$ as the glucose was increased to between 6 and $7 \mathrm{mM}$. Corresponding values in the subjects with GCK mutations over the same glucose intervals were $38 \pm 5$ and $59 \pm 5 \mathrm{pmol} / \mathrm{min}$, respectively. ISRs for the patients and controls for $1 \mathrm{mM}$ glucose increments are shown in the lower panel of Fig. 3. Over the concentration range between
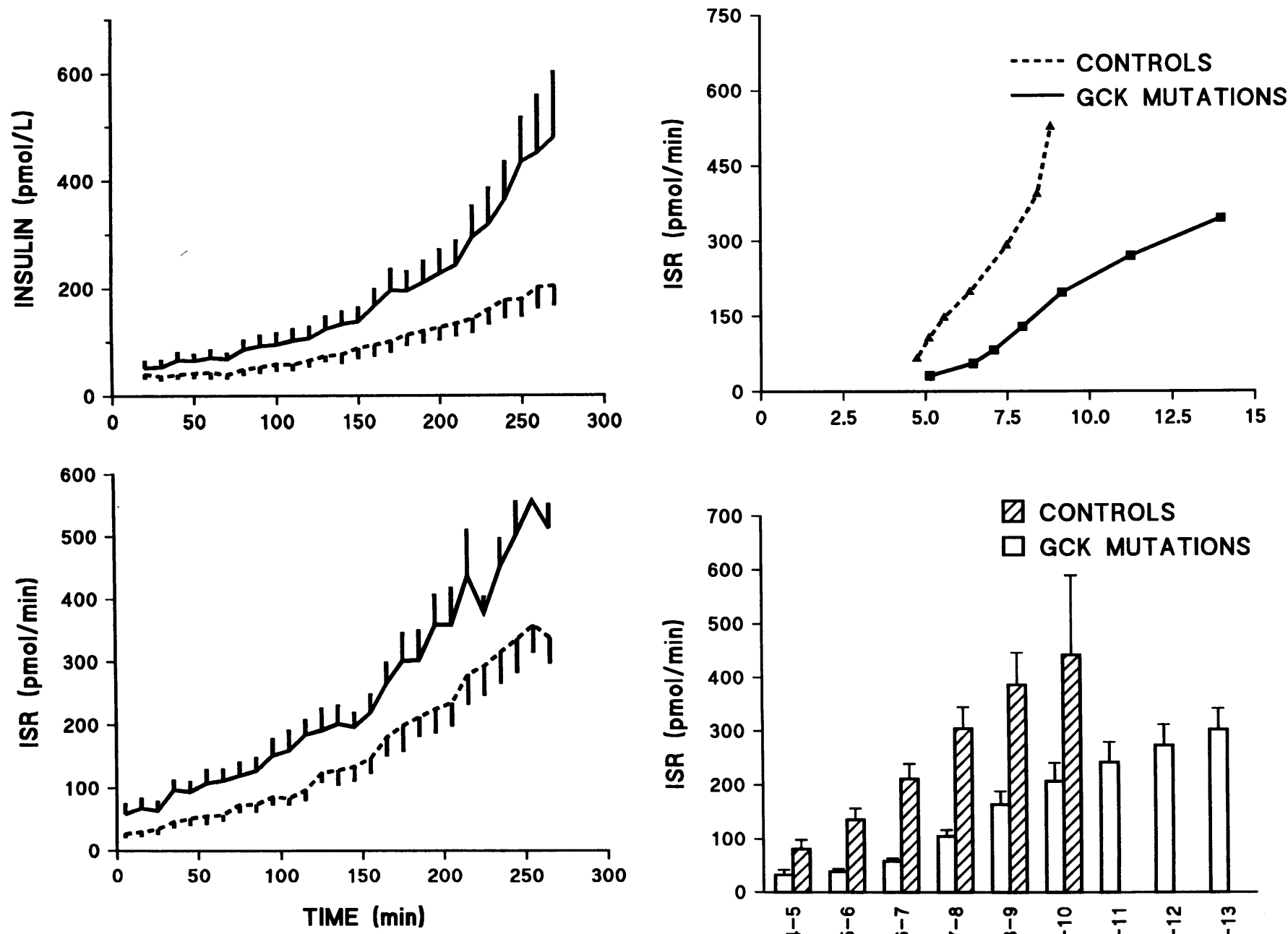

Figure 2. Average glucose, ISR, and insulin profiles in the subjects with GCK mutations and their matched controls during the stepped glucose infusion studies. After a 30-min period of baseline sampling glucose was infused at rates $1,2,3,4,6$, and $8 \mathrm{mg} / \mathrm{kg}$ per min. Each infusion rate was administered for a period of $40 \mathrm{~min}$ and glucose, insulin, and C-peptide were measured 10, 20, 30, and 40 min into each period.

nificantly higher $(8.7 \pm 0.5$ vs. $6.7 \pm 0.3 \mathrm{mM}, P<0.002)$ and ISRs were significantly lower ( $159 \pm 19$ vs. $246 \pm 27 \mathrm{pmol} / \mathrm{min}$, $P<0.04)$ in the subjects with GCK mutations.

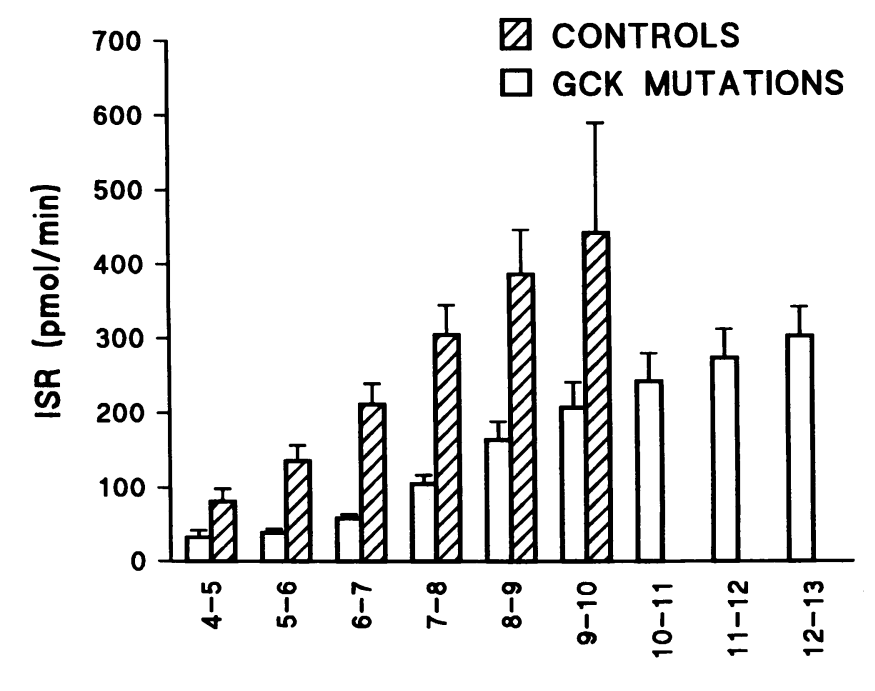

\section{GLUCOSE (mmol/L)}

Figure 3. Top panel: Relationship between average glucose concentrations and insulin secretion rates during the graded intravenous glucose infusion studies. The lowest glucose levels and insulin secretion rates were measured under basal conditions and subsequent levels were obtained during glucose infusion rates of $1,2,3,4,6$, and 8 $\mathrm{mg} / \mathrm{kg}$ per min, respectively. Bottom panel: Average insulin secretion rates for subjects with GCK mutations and controls over $1 \mathrm{mM}$ glucose intervals during graded intravenous glucose infusion. 
5 and $9 \mathrm{mM}$ glucose, the controls secreted on average $252 \pm 35$ $\mathrm{pmol} / \mathrm{min}$ and the subjects with GCK mutations $91 \pm 11 \mathrm{pmol} /$ $\min (P<0.006)$. Thus ISRs were reduced by $61 \%$ in subjects with GCK mutations. Individual average ISRs and insulins over the 5-9 $\mathrm{mM}$ concentration range are listed in Table II.

In order to define the profile of responsiveness of the $\beta$ cell to increases in plasma glucose, the absolute and relative slopes of the curves relating glucose and ISR were compared for specific glucose concentration intervals. Over a range spanning glucose intervals between 5 and $9 \mathrm{mM}$ the average slope in the controls was $87 \pm 18 \mathrm{pmol} /(\mathrm{min} \times \mathrm{mM})$. The local slopes for $0.5 \mathrm{mM}$ glucose intervals over this range were calculated and compared by repeated measures analysis of variance. No significant differences were found $(P>0.16)$, compatible with the conclusion that in the control group, the relationship between glucose and ISR is linear over this range of glucose levels. In contrast, in the subjects with GCK mutations, repeated measures analysis of variance showed significant differences in the slopes between different $0.5 \mathrm{mM}$ glucose intervals $(P<0.002)$. At lower glucose levels in the range of 5.5-6.0 mM, the absolute slope of the dose-response curve was only $11 \pm 2 \mathrm{pmol} /$ $(\min \times \mathrm{mM})$ but increased to $61 \pm 8 \mathrm{pmol} /(\mathrm{min} \times \mathrm{mM})$ as the glucose level increased to the $8.0-8.5 \mathrm{mM}$ interval, indicating that in the normal physiological glucose range, the relationship between glucose and ISR is nonlinear in patients with GCK mutations. The relationship between glucose and ISR at different glucose intervals was further explored by examining the changes in the relative rather than the absolute slopes of the curve relating these two variables (Fig. 4). The relative slope which represents the incremental response of the $\beta$ cell to a standard increment in glucose concentration was taken to represent a measure of $\beta$-cell responsiveness to glucose at different glucose levels. In the controls, the relative slope expressed as a percentage of the average ISR at the corresponding glucose level was greatest for the $5.5-6.0 \mathrm{mM}$ glucose interval at $82 \pm 16 \% / \mathrm{mM}(P<0.01$ by repeated measures analysis of variance). In the subjects with GCK mutations, the relative slope was only $35 \pm 5 \% / \mathrm{mM}$ for this glucose interval $(P<0.04$ versus control) but increased to $70 \pm 10$ and $74 \pm 7 \% / \mathrm{mM}$ at the $6.5-$

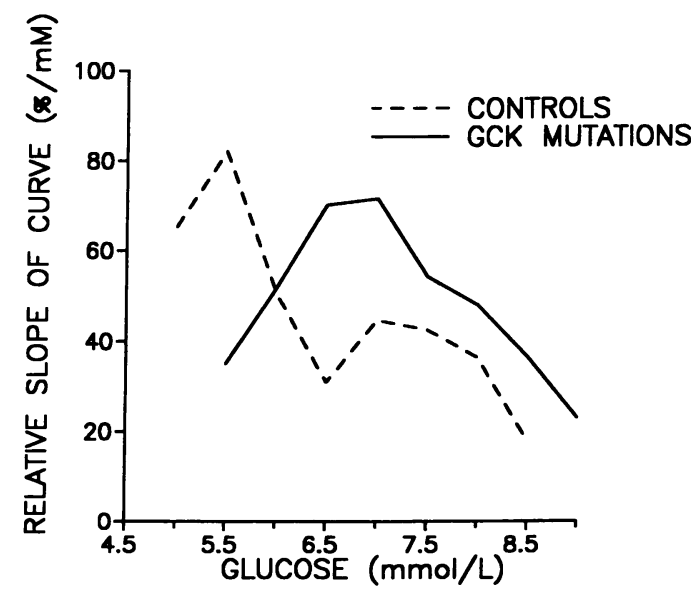

Figure 4. Alterations in $\beta$-cell responsiveness in relation to changes in the plasma glucose concentration. The relative slope of ISR for 0.5 $\mathrm{mM}$ increments in glucose was calculated as outlined under Methods and the changes are shown in relation to the corresponding glucose concentrations.
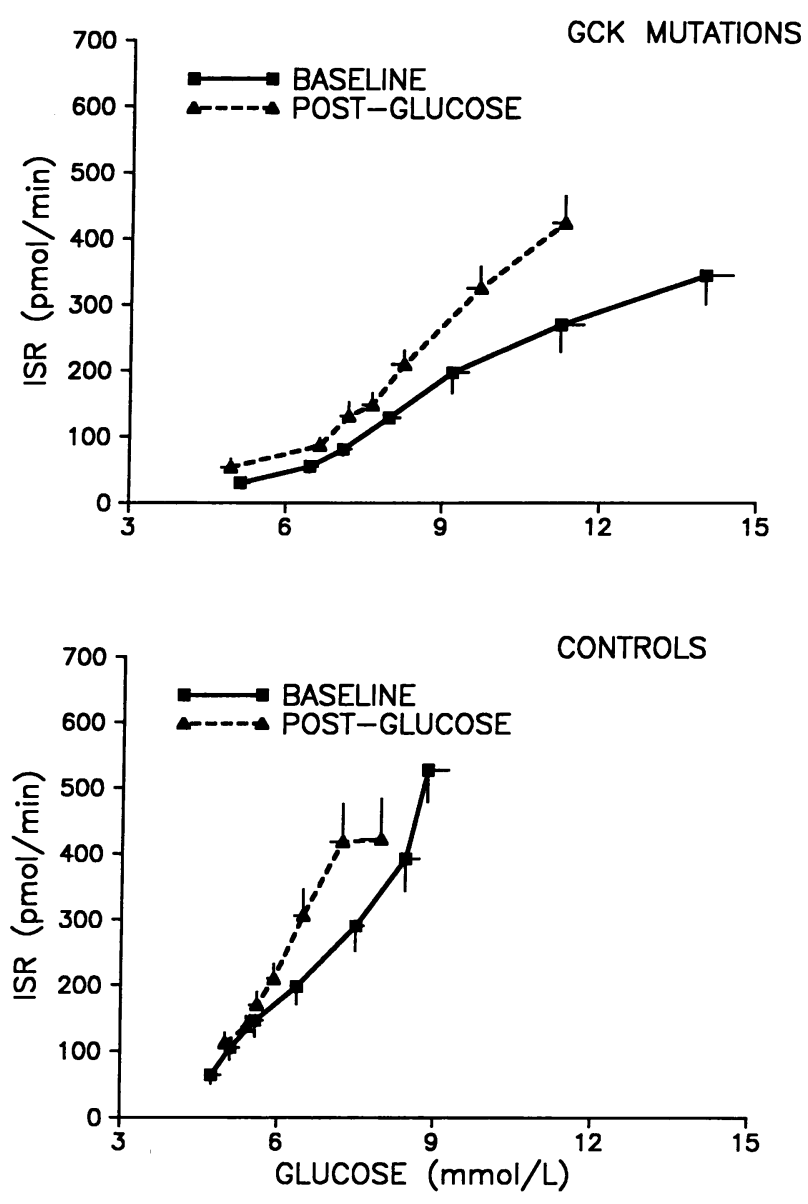

Figure 5. Graded intravenous glucose infusions were administered to subjects with GCK mutations and controls after an overnight fast (baseline) and after a 42-h intravenous infusion of glucose (post-glucose) at a rate of $4-6 \mathrm{mg} / \mathrm{kg} / \mathrm{min}$.

7.0 and $7.0-7.5 \mathrm{mM}$ intervals respectively $(P<0.001$ by repeated measures analysis of variance). These results indicate that in both groups, $\beta$-cell responsiveness is greatest at and slightly above the fasting glucose level pertaining to each group.

Effects of glucose infusion on relationships between glucose and ISR

Mean glucose levels achieved during the 42 -h constant glucose infusion were $9.7 \pm 0.2 \mathrm{mM}$ in the subjects with GCK mutations and $6.8 \pm 0.2 \mathrm{mM}$ in the controls $(P<0.0002)$. The glucose infusion was discontinued after $42 \mathrm{~h}$ and low-dose insulin was administered resulting in a fall in the plasma glucose concentration to similar levels in the two groups $(5.0 \pm 0.1 \mathrm{vs}$. $4.9 \pm 0.2 \mathrm{mM}, P>0.74)$. The graded intravenous glucose infusion study was then repeated in each subject.

In order to allow ISRs to be compared at the same glucose concentrations before and after glucose infusion, average ISRs measured during each glucose infusion rate were plotted against the average glucose concentrations (Fig. 5). These data demonstrate that the 42 -h glucose infusion resulted in a shift in the glucose/ISR dose-response curves to the left in both groups, ISR increasing by $45 \%$ in the subjects with GCK mutations over a glucose range of 5-9 $\mathrm{mM}(P<0.002)$ and by $24 \%$ in controls over the same glucose range $(P<0.0005)$. 


\section{Ultradian oscillations of insulin secretion}

During the 12-h oscillatory glucose infusion, glucose concentrations were significantly higher in the subjects with GCK mutations than in the controls $(13.1 \pm 0.3$ vs. $8.2 \pm 0.2 \mathrm{mM}, P$ $<0.0001)$. The ISR was not significantly different between subjects and controls $(295 \pm 28$ vs. $309 \pm 40 \mathrm{pmol} / \mathrm{min})$. The average absolute amplitude of the ultradian oscillations in ISR tended to be lower in the subjects with GCK mutations than in the controls despite the higher glucose levels in this group, but the differences were not statistically significant ( $151 \pm 32$ vs. $213 \pm 40 \mathrm{pmol} / \mathrm{min}, P>0.23$ ). Fig. 6 shows the temporal profiles of glucose and ISR in a representative subject with a mutation and his control. Spectral analysis of the glucose and ISR profiles showed that as a group, the subjects with GCK mutations demonstrated abnormalities in entrainment by exogenous glucose (Fig. 7). In this representation the peaks if any correspond to the dominant periodicity in the temporal variation. The normalized spectral power at $144 \mathrm{~min}$ was significantly less in the patients than in their controls, for glucose ( $12.3 \pm 0.3$ vs. $19.3 \pm 0.5, P<0.001)$, ISR $(2.5 \pm 1.1$ vs. $9.8 \pm 1.1$, $P<0.02)$, and insulin $(2.8 \pm 1.1$ vs. $10.0, P<0.005)$. Furthermore, there was complete separation with no overlap between the spectral powers observed in the individual subjects from the two groups.

\section{Relationship between in vitro enzyme activity and in vivo ISRs}

The activity of each of the mutant enzymes present in these subjects has been defined in vitro (15). $K_{\mathrm{m}}$ and $V_{\max }$ parameters for each enzyme are shown in Table III in addition to the average ISRs measured during the graded intravenous glucose infusion studies. Individual data from this study in relation to the average results in the controls are shown in Fig. 8 and Table III. Three subjects with mutations that resulted in the most severe reductions in enzymatic activity (GK2, GK3, and GK6) had the lowest ISRs in vivo. Two subjects (GK4 and GK5) whose mutations resulted in the mildest impairment of in vitro biological activity demonstrated insulin secretion rates which were on average $34 \%$ higher than the three subjects with the severe mutations but $58 \%$ lower than the controls. A single subject (GK7) whose mutation resulted in an almost inactive enzyme in vitro showed higher ISRs than any of the other subjects with mutations.

\section{Discussion}

Our understanding of the pathophysiology of NIDDM is incomplete for a variety of reasons. The disorder is heterogeneous from both clinical and genetic standpoints and an elevation in the plasma glucose results in defects in the pathways of insulin secretion and insulin action making it impossible to differentiate between primary and secondary defects (16). A specific subtype of NIDDM with age at onset of $<25 \mathrm{yr}$ of age and autosomal dominant inheritance has been recognized (17). This early-onset form of NIDDM has been called maturity-onset diabetes of the young and appears to be due to a limited number of discrete genetic defects $(1,4,18,19)$. One form of this disorder results from mutations in the glycolytic enzyme GCK. This enzyme is the first rate-limiting step in glucose metabolism by the $\beta$ cell and has been postulated to represent the glucose sensor (20). Detailed studies of subjects with GCK mutations provides a unique opportunity to define the role of GCK in the regulation of insulin secretion and to understand the pathophysiology of the glucose intolerance which occurs in these patients.

The results indicate that GCK mutations are associated with a diminished ability of the $\beta$ cell to respond to small increments in the plasma glucose concentration resulting in a down-
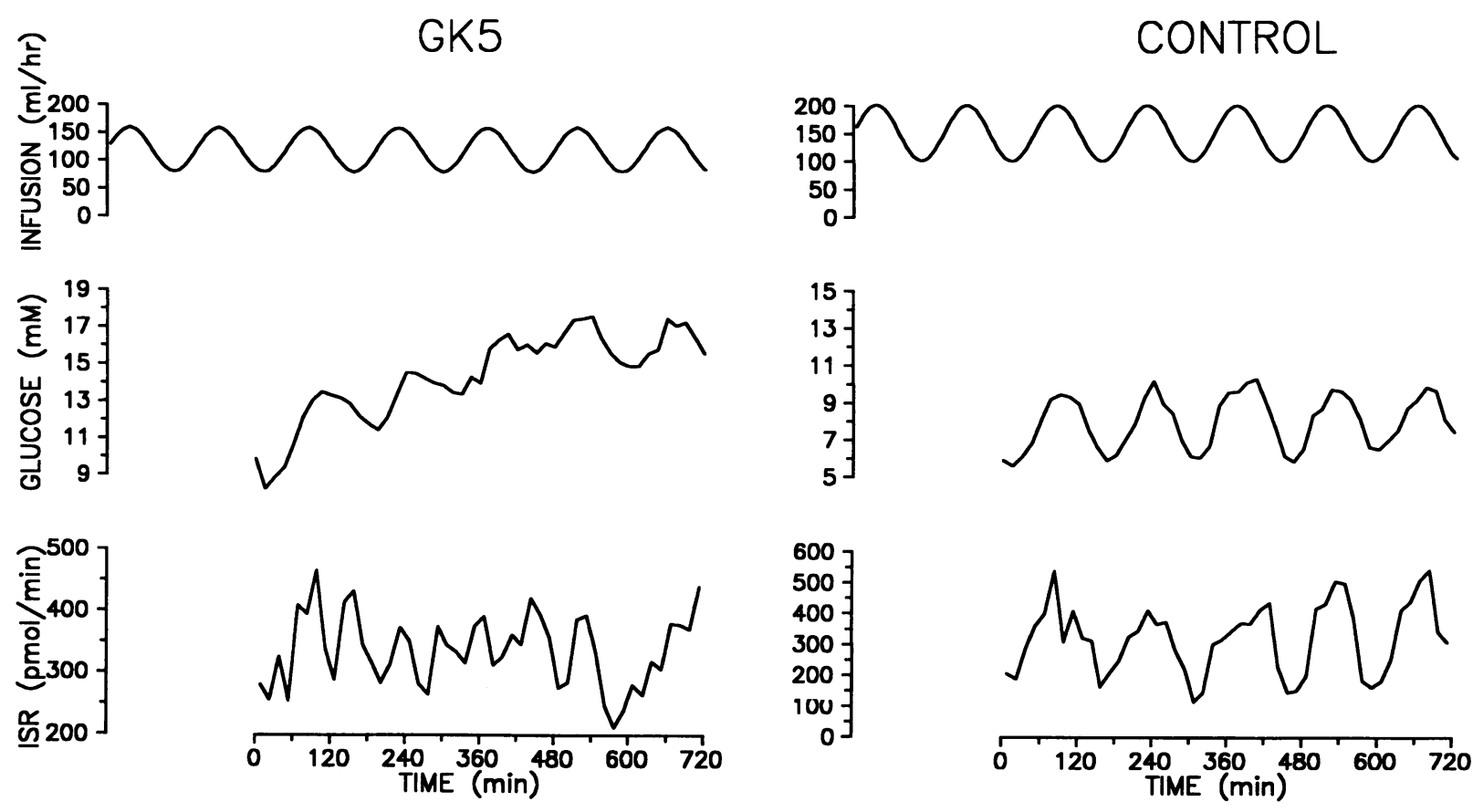

Figure 6. Profile of glucose and insulin secretion rate from a subject with a GCK mutation (left) and a control (right) during the administration of glucose in an oscillatory pattern with a period of $144 \mathrm{~min}$. 

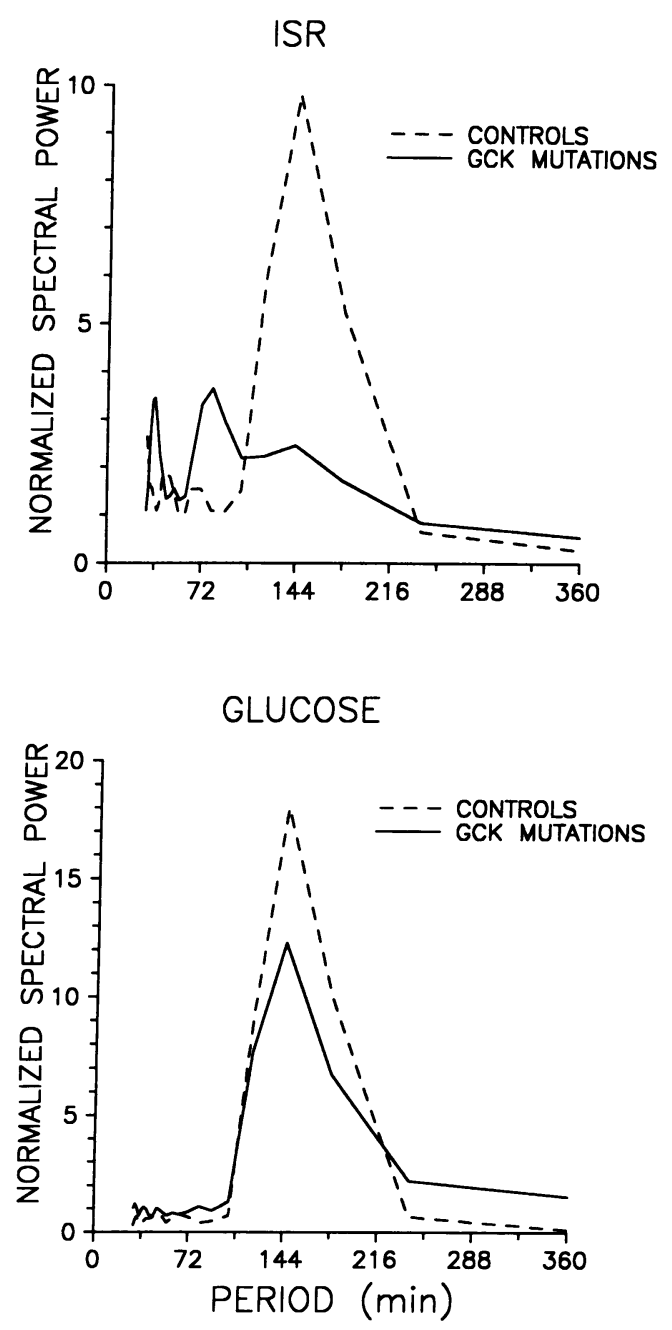

Figure 7. Average power of the spectra obtained from the glucose and ISR profiles from four subjects with GCK mutations and matched controls who received oscillatory glucose infusions with a period of $144 \mathrm{~min}$.

ward and/or rightward shift in the glucose/ISR dose-response curve. The differences between subjects with GCK mutations and controls were most clearly seen during graded low-dose intravenous glucose infusions. In the controls, the relationship between glucose and ISR was linear over the range of concentrations encountered under normal physiological circumstances, i.e., between 5 and $9 \mathrm{mM}$. However when the relative increment in insulin secretion induced by small increments in glucose was studied, the $\beta$ cell was found to be most sensitive to glucose levels that define the normal fasting range, i.e., 5.5-6.0 $\mathrm{mM}$. In contrast, in the subjects with GCK mutations, the relationship between glucose and ISR was not linear because the $\beta$ cell was poorly responsive to glucose within the normal fasting range as defined above, and the point of maximal responsiveness (defined as the point on the dose-response curve where the local relative slope is maximal) was increased to 6.5-7.5 $\mathrm{mM}$. This level corresponded very closely to the fasting plasma glucose concentration seen in these patients. These data are consistent with the conclusion that the fasting plasma glucose concentration in controls and subjects with GCK mutations is determined by the point at which the $\beta$ cell is maximally responsive to a small increment in plasma glucose.
Table III. In Vitro Enzymatic Activity $\left(V_{\max }\right.$ and $\left.K_{m}\right)$ for Each of the Mutant GCK Enzymes

\begin{tabular}{lcccc}
\hline Subjects & Pedigree $^{*}$ & Mutation $^{*}$ & $V_{\max }$ & $\begin{array}{c}K_{\mathrm{m}} \\
\text { (glucose) }\end{array}$ \\
\hline & & & $U / m g$ & $m M$ \\
GK2 & F8 & E279X & - & - \\
GK3 & F331 & V182M & $49 \pm 6$ & $70 \pm 9$ \\
GK4 & F51 & E300Q & $100 \pm 8$ & $20 \pm 1.2$ \\
GK5 & F51 & E300Q & $100 \pm 8$ & $20 \pm 1.2$ \\
GK6 & F390 & G261R & $\leq 0.46$ & $2.5 \pm 2.1$ \\
GK7 & F422 & V203A & $0.5 \pm 0.04$ & $100 \pm 20$ \\
Controls & - & - & $100 \pm 8$ & $8 \pm 2$ \\
& & & & \\
\hline
\end{tabular}

* Data were obtained from Froguel et al. (4). ${ }^{\ddagger}$ The single-letter abbreviations for the amino acids are used: A, alanine; E, glutamic acid; $\mathrm{G}$, glycine; $\mathrm{M}$, methionine; $\mathrm{Q}$, glutamine; $\mathrm{R}$, arginine; $\mathrm{V}$, valine; and $\mathrm{X}$, stop. The notation E279X means that the codon for glutamic acid 279 has been mutated to a translational stop codon. ${ }^{8}$ Data from Gidh-Jain et al. (15).

Additional studies demonstrated that the responsiveness of the $\beta$ cell is improved after the intravenous administration of low doses of glucose for a period of $42 \mathrm{~h}$. After the glucose infusion, the glucose ISR dose-response curve was shifted to the left in the subjects with GCK mutations and the insulin secretory responses at each glucose concentration increased by $\sim 45 \%$. The increase in insulin secretion induced by this glucose infusion was even greater in the subjects with mutations than in the controls. The present experimental design does not allow us to determine if this was due to the higher glucose concentrations achieved in the patients with mutations. Studies performed in vivo and in vitro have previously demonstrated that insulin secretory responses can be increased by

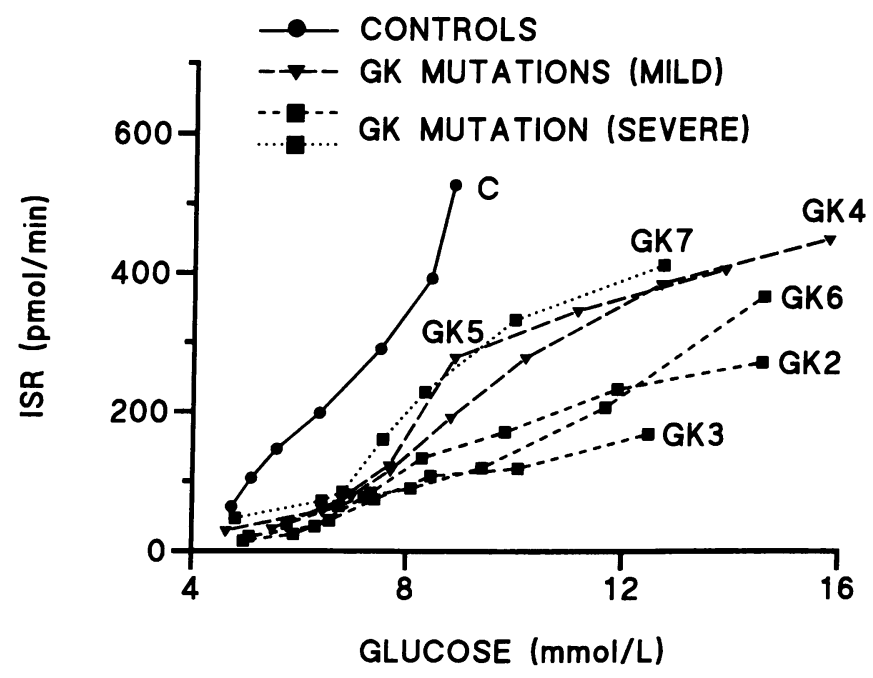

Figure 8. Relationship between glucose and ISR during graded intravenous glucose infusions. The average curve based on data from six controls is shown in relation to individual data from the six subjects with GCK mutations. Subjects GK2, GK3, and GK6 had mutations that resulted in severe impairment of in vitro glucokinase enzyme activity as did subject GK7. The mutations in subjects in subjects GK4 and GK5 resulted in only mild reductions in enzyme activity in vitro. 
exposure to glucose (21-31). The present findings are consistent with these previous results and indicate that even the severely reduced ISRs found in subjects with GCK mutations can be improved by physiological stimuli such as glucose. We assume that this increase in insulin responsiveness results from increased levels of glucokinase activity in the $\beta$-cell $(25,32)$. There is considerable evidence that prolonged exposure of the $\beta$ cell to high glucose may induce defects in insulin secretion and insulin secretory responses in patients with classic NIDDM which are improved by interventions which lower the plasma glucose concentration (33). The improvement in $\beta$ cell responsiveness after glucose infusion in the subjects with GCK mutations may represent a means of differentiating physiologically between NIDDM owing to GCK mutations and classic NIDDM where chronic exposure to high glucose would be expected to lead to further impairment in insulin secretion. The possibility that such an approach could allow different forms of NIDDM to be differentiated will need to be addressed in future studies.

Insulin secretory responses were also evaluated over a 24-h period while the subjects consumed a weight maintenance diet consisting of three meals. Under these conditions, subjects with GCK mutations demonstrated fasting plasma glucose concentrations of $\sim 7.0 \mathrm{mM}$ and peak postprandial levels $\sim 10 \mathrm{mM}$. Although reduced insulin secretory responses to breakfast were seen in the subjects with GCK mutations, fasting, postprandial responses to lunch and dinner, and 24-h insulin secretion rates were not significantly different from controls and the delayed and blunted insulin secretory responses to meals characteristic of classic NIDDM were not seen (34).

Ultradian oscillations in insulin secretion were evaluated during oscillatory glucose infusions with an oscillatory period of $144 \mathrm{~min}$. These experiments were designed to determine whether the periodicity of the ultradian oscillations could be entrained to the frequency of the exogenous glucose stimulus. The concept of entrainment is central to the field of nonlinear dynamics. Briefly, if a nonlinear, self-oscillating system is perturbed exogenously with a periodic stimulus, different types of oscillatory behaviors may emerge, one of which is entrainment. When entrainment occurs, the oscillation of the system reacts to the exogenous stimulus by adjusting its period to that of the stimulus. In contrast to the controls where the oscillatory glucose infusion resulted in entrainment of plasma glucose and insulin secretion, neither the glucose nor the ISR pattern was entrained in the subjects with GCK mutations. As a result, significant abnormalities in the interactions between the ultradian oscillations of ISR and glucose were evident by spectral analysis and the spectral power at $144 \mathrm{~min}$ for both glucose and insulin secretion was significantly reduced in the subjects with GCK mutations. The strength of this result is highlighted by the fact that there was no overlap in the results obtained in subjects from the two groups. The lack of entrainment of ISR is consistent with previous data in patients with classic NIDDM or impaired glucose tolerance (35). However, in these latter two groups, entrainment of the glucose profiles was seen. The lack of entrainment of glucose in subjects with GCK mutations could be related to abnormal control of hepatic glucose metabolism since the mutations are expressed in both liver and $\beta$ cell. Furthermore, in contrast to our previous study which was performed in insulin resistant IGT and NIDDM patients, use of the homeostasis model assessment method showed that the subjects with GCK mutations in the present study were rela- tively insulin sensitive. The abnormal insulin secretory pattern would be expected to affect peripheral glucose utilization (and therefore the glucose concentration profile) to a larger degree in lean, insulin-sensitive subjects than in obese, insulin-resistant subjects in whom the response to an increase in plasma insulin level has been shown to be sluggish (36). Our previous studies in subjects with impaired glucose tolerance demonstrated normal number but reduced amplitude of the ultradian oscillations of insulin secretion. Differences in the amplitude of the ultradian oscillation between subjects with GCK mutations and controls did not reach statistical significance in the present study ( $151 \pm 32$ vs. $213 \pm 40 \mathrm{pmol} / \mathrm{min}, P<0.23$ ). However, it should be borne in mind that glucose concentrations were significantly higher in the subjects with GCK mutations during the oscillatory glucose infusions $(13.1 \pm 0.3$ vs. $8.2 \pm 0.2 \mathrm{mM}, P$ $<0.0001)$. Since an increase in plasma glucose results in an increase in the amplitude of the ultradian oscillations (37), this difference in glucose almost certainly masked what would have been significant differences in the amplitude of the ultradian insulin secretory oscillations between the two groups.

During intravenous glucose tolerance testing, first-phase insulin secretory responses were not different from control in subjects with GCK mutations. These findings are consistent with previous results (5) but the interpretation of the significance of this finding is complicated in light of the fact that plasma glucose levels were higher in the subjects with GCK mutations during this test. If the plasma glucose concentrations had been the same in the two groups, the subjects with GCK mutations may have demonstrated reduced first-phase secretory responses. It thus appears that subjects with GCK mutations are able to compensate for increases in plasma glucose levels by increasing their ISRs and this may mask differences in ISRs between subjects with mutations and controls during tests such as intravenous glucose tolerance tests and 24-h meal studies where differences in glucose cannot be avoided. Tests that are not critically dependent on the absolute level of glucose such as the entrainment of ultradian oscillations of secretion or in which differences in glucose can be accounted for in the analysis, such as defining the glucose insulin secretion dose-response relationships, appear to be more sensitive measures of $\beta$-cell dysfunction in subjects with GCK mutations than the intravenous glucose tolerance test or 24-h meal profile. This result appears to be in contrast with results in classic NIDDM where first phase secretory responses are reduced despite differences in glucose (16).

The enzymatic properties of the GCK mutants found in the six patients studied here have been determined (15). This has allowed us to compare in vitro enzyme activity as judged by $V_{\max }$ and $K_{\mathrm{m}}$ with the in vivo effects on ISRs. A number of conclusions can be drawn from these comparisons. Four patients (GK2, GK3, GK6, and GK7) expressed mutant enzymes that were either non-functional because of a nonsense mutation or a mutation that had markedly reduced enzyme activity. In three of these subjects (GK2, GK3, and GK6) ISRs were markedly reduced during the graded glucose infusions and represented only $28 \%$ of the amount of insulin secreted by the controls. The fourth subject in this group (GK7) secreted more insulin than any of the six subjects with GCK mutations although this still represented only $52 \%$ of the amount secreted by the controls. Two subjects (GK4 and GK5) had mutations that had no effect on $V_{\max }$ but increased the $K_{\mathrm{m}}$ for glucose from 8 to $20 \mathrm{mM}$. These patients secreted $34 \%$ more insulin 
than the three subjects with severe mutations described above but their ISRs were still $58 \%$ less than the controls. Thus, it appears that even mutations that have only a relatively small effect on the kinetic properties of GCK in vitro can impair insulin secretory responses to graded low-dose infusions of glucose. In some cases, however, as demonstrated by subject GK7, the severity of the in vivo secretory defect is not completely predicted by the in vitro enzyme activity, suggesting that additional compensatory factors may be operative.

In summary, the present studies support the notion that glucokinase plays a key role in the ability of the $\beta$ cell to sense small alterations in the plasma glucose concentration. The glucose/insulin secretion dose-response curve is shifted to the right in subjects with mutations in this enzyme and the $\beta$ cell demonstrates maximal responsiveness not at glucose concentrations between 5.5 and $6.0 \mathrm{mM}$ as in controls but at concentrations of 6.5-7.5 mM. This results in an increase in the fasting and postprandial glucose concentrations and may mask differences in insulin secretory responses. Mutations which cause only mild impairment of in vitro enzyme activity are associated with severe reductions in insulin secretory rates and factors such as exposure to high glucose appear to result in a compensatory increase in in vivo insulin secretion. The normal pattern of ISR response to meals is largely retained although reduced insulin secretory responses to the breakfast meal were seen. The number of ultradian oscillations is normal in subjects with GCK mutations although they demonstrate reduced ability to be entrained by exogenous glucose presumably due to decreased glucose sensing ability by the $\beta$ cell. Mutations in the enzyme therefore result in a discrete clinical and genetic syndrome of mild elevations in fasting and postprandial glucose concentrations with characteristic alterations in the pattern of insulin secretory responses to glucose.

\section{Acknowledgments}

The authors wish to thank the nursing staff of the Clinical Research Center at the University of Chicago, particularly Jacqueline Imperial, R.N., for expert care of the subjects who participated in the study. The authors also appreciate the technical contributions of Mr. Paul Rue and Ms. Marsha Jackson.

This work was supported by National Institutes of Health grants DK-31842, DK-44840, DK-20595 (Diabetes Research and Training Center), and RR-00055 (Clinical Research Center), the Howard Hughes Medical Institute, Eli Lilly and Company, the LIPHA company, Boehringer-Mannheim, Association Francaise Centre les Myopathies through the Généthon program, the Assistance PubliqueHôpitaux de Paris, and the French Ministry for Research and Technology. Dr. Sturis was the recipient of a postdoctoral fellowship from the Juvenile Diabetes Foundation International, and Dr. Stoffel was supported by a fellowship from the Deutsche Forschungsgemeinschaft and Dr. Clément by "Les Amis de la Science."

\section{References}

1. Froguel, P., M. Vaxillaire, F. Sun, G. Velho, H. Zouali, M. O. Butel, S. Lesage, N. Vionnet, K. Clement, F. Fougerousse, et al. 1992. Close linkage of glucokinase locus on chromosome $7 p$ to early-onset non-insulin-dependent diabetes mellitus. Nature (Lond.) 356:162-164.

2. Vionnet, N., M. Stoffel, J. Takeda, K. Yasuda, G. I. Bell, H. Zouali, S. Lesage, G. Velho, F. Iris, P. Passa, et al. 1992. Nonsense mutation in the glucokinase gene causes early-onset non-insulin-dependent diabetes mellitus. Nature (Lond.). 356:721-722.
3. Hattersley, A. T., R. C. Turner, M. A. Permutt, P. Patel, Y. Tanizawa, K. C. Chiu, S. O'Rahilly, P. J. Watkins, and J. S. Wainscoat. 1992. Linkage of type 2 diabetes to the glucokinase gene. Lancet. 339(8805):1307-1310.

4. Froguel, P., H. Zouali, N. Vionnet, G. Velho, M. Vaxillaire, F. Sun, S. Lesage, M. Stoffel, J. Takeda, P. Passa, et al. 1993. Familial hyperglycemia due to mutations in glucokinase. N. Engl. J. Med. 328:697-702.

5. Velho, G., P. Froguel, K. Clement, M. E. Pueyo, B. Rakotoambinina, H. Zouali, P. Passa, D. Cohen, and J.-J. Robert. 1992. Primary pancreatic beta-cell secretory defect caused by mutations in glucokinase gene in kindreds of maturity onset diabetes of the young. Lancet. 340:444-448.

6. Stoffel, M., P. Froguel, J. Takeda, H. Zouali, N. Vionnet, S. Nishi, I. T. Weber, R. W. Harrison, S. J. Pilkis, S. Lesage, et al. 1992. Human glucokinase gene: Isolation, characterization, and identification of two missense mutations linked to early-onset non-insulin-dependent (type 2) diabetes mellitus. Proc. Natl. Acad. Sci. USA. 89:7698-7702.

7. Tchobroutsky, G. 1991. Blood glucose levels in diabetic and non-diabetic subjects. Diabetologia. 34:67-73.

8. Matthews, D. R., J. P. Hosker, A. S. Rudenski, B. A. Naylor, D. F. Treacher, and R. C. Turner. 1985. Homeostasis model assessment: insulin resistance and B-cell function from fasting plasma glucose and insulin concentrations in man. Diabetologia. 28:412-419.

9. Polonsky, K. S., J. Licinio-Paixao, B. D. Given, W. Pugh, P. Rue, J. Galloway, T. Karrison, and B. Frank. 1986. Use of biosynthetic human C-peptide in the measurement of insulin secretion rates in normal volunteers and type I diabetic patients. J. Clin. Invest. 77:98-105.

10. Eaton, R. P., R. C. Allen, and D. S. Schade. 1980. Prehepatic insulin production in man: Kinetic analysis using peripheral connecting peptide behaviour. J. Clin. Endocrinol. Metab. 51:520-528.

11. Morgan, C. R., and A. Lazarow. 1963. Immunoassay of insulin: two antibody system: plasma insulin levels of normal, subdiabetic and diabetic rats. Diabetes. 12:115-126.

12. Faber, O. K., C. Binder, J. Markussen, L. G. Heding, V. K. Naithani, H. Kuzuya, P. Blix, D. L. Horwitz, and A. H. Rubenstein. 1978. Characterization of seven C-peptide antisera. Diabetes. 27(Suppl. 1):170-177.

13. Van Cauter, E. 1988. Estimating false-positive and false-negative errors in analyses of hormonal pulsatility. Am. J. Physiol. 254:E786-E794.

14. Jenkins, G. M., and D. G. Watts. 1968. Spectral Analysis and Its Applications. Holden Day, San Francisco, 525 pp.

15. Gidh-Jain, M., J. Takeda, L. Z. Xu, A. J. Lange, N. Vionnet, M. Stoffel, P. Froguel, G. Velho, F. Sun, D. Cohen, et al. 1993. Glucokinase mutations associated with non-insulin-dependent ( type 2) diabetes mellitus have decreased enzymatic activity: implications for structure/function relationships. Proc. Natl. Acad. Sci. USA. 90:1932-1936.

16. DeFronzo, R. A., R. C. Bonadonna, and E. Ferrannini. 1992. Pathogenesis of NIDDM: a balanced overview. Diabetes Care. 15:318-368.

17. Fajans, S. S. 1990. Scope and heterogeneous nature of MODY. Diabetes Care. 13:49-64.

18. Bell, G. I., K. S. Xiang, M. V. Newman, S. Wu, L. G. Wright, S. S. Fajans, R. S. Spielman, and N. J. Cox. 1991. Gene for non-insulin-dependent diabetes mellitus (maturity-onset diabetes of the young subtype) is linked to DNA polymorphism on human chromosome 20q. Proc. Natl. Acad. Sci. USA. 88:14841488 .

19. Weir, G. C. 1993. A defective beta-cell glucose sensor as a cause of diabetes. N. Engl. J. Med. 328:729-731.

20. Matschinsky, F. M. 1990. Glucokinase as glucose sensor and metabolic signal generator in pancreatic beta-cells and hepatocytes. Diabetes. 39:647-652.

21. Ward, W. K., J. B. Halter, J. C. Beard, and D. Porte. 1984. Adaptation of B and $A$ cell function during prolonged glucose infusion in human subjects. Am. J. Physiol. 246:E405-E411.

22. Brelje, T. C., and R. L. Sorenson. 1988. Nutrient and hormonal regulation of the threshold for glucose-stimulated insulin secretion in isolated rat pancreas. Endocrinology. 123:1582-1590.

23. Timmers, K. I., A. M. Powell, N. R. Voyles, D. Solomon, S. D. Wilkins, S Bhathena, and L. Recant. 1990. Multiple alterations in insulin responses to glucose in islets from 48-h glucose-infused nondiabetic rats. Diabetes. 39:14361444.

24. Marynissen, G., V. Leclercq-Meyer, A. Sener, and W. J. Malaisse. 1990. Perturbation of pancreatic islet function in glucose-infused rats. Metab. Clin. Exp. 39:87-95.

25. Liang, Y., H. Najafi, R. M. Smith, E. C. Zimmerman, M. A. Magnuson, M. Tal, and F. M. Matschinsky. 1992. Concordant glucose induction of glucokinase, glucose usage, and glucose-stimulated insulin release in pancreatic islets maintained in organ culture. Diabetes. 41:792-806.

26. Bedoya, F. J., F. M. Matschinsky, T. Shimizu, J. J. O'Neil, and M. C. Appel. 1986. Differential regulation of glucokinase activity in pancreatic islets. $J$. Biol. Chem. 261:10760-10764.

27. Van Haeften, T. W., G. A. Voetberg, J. E. Gerich, and E. A. Van Der Veen. 1989. Dose-response characteristics for arginine-stimulated insulin secretion in man and influence of hyperglycemia. J. Clin. Endocrinol. Metab. 69:1059-1064. 
28. Levin, S. R., J. H. Karam, S. Hane, G. M. Grodsky, and P. H. Forsham. 1971. Enhancement of arginine-induced insulin secretion in man by prior administration of glucose. Diabetes. 20:171-176.

29. Levin, J. R., G. M. Grodsky, R. Hagura, D. F. Smith, and P. H. Forsham. 1972. Relationship between arginine and glucose in the induction of insulin secretion from the isolated, perfused rat pancreas. Endocrinology. 90:624-631.

30. Ward, W. K., B. J. Wallum, J. C. Beard, G. H. Taborsky, and D. Porte. 1988. Reduction of glycemic potentiation: sensitive indicator of B-cell loss in partially pancreatectomized dogs. Diabetes. 37:723-729.

31. Halter, J. B., R. J. Graf, and D. Porte. 1979. Potentiation of insulin secretory responses by plasma glucose levels in man: evidence that hyperglycemia in diabetes compensates for impaired glucose potentiation. J. Clin. Endocrinol. Metab. 48:946-954.

32. Meglasson, M. D., and F. M. Matschinsky. 1986. Pancreatic islet glucose metabolism and regulation of insulin secretion. Diabetes/Metab. Rev. 2:163214.
33. Leahy, J. L., S. Bonner-Weir, and G. C. Weir. 1992. B-cell dysfunction induced by chronic hyperglycemia. Diabetes Care. 15:442-455.

34. Polonsky, K. S., B. D. Given, L. J. Hirsch, H. Tillil, E. T. Shapiro, C. Beebe, B. H. Frank, J. A. Galloway, and E. Van Cauter. 1988. Abnormal patterns of insulin secretion in non-insulin dependent diabetes mellitus. N. Engl. J. Med. 318:1231-1239.

35. O'Meara, N. M., J. Sturis, E. Van Cauter, and K. S. Polonsky. 1993. Lack of control by glucose of ultradian insulin secretory oscillations in impaired glucose tolerance and in non-insulin-dependent diabetes mellitus. J. Clin. Invest. 92:262-271.

36. Prager, R., P. Wallace, and J. M. Olefsky. 1986. In vivo kinetics of insulin action on peripheral glucose disposal and hepatic glucose output in normal and obese subjects. J. Clin. Invest. 78:472-481.

37. Sturis, J., N. M. O'Meara, E. T. Shapiro, J. D. Blackman, H. Tillil, K. S. Polonsky, and E. Van Cauter. 1993. Differential effects of glucose stimulation upon rapid pulses and ultradian oscillations of insulin secretion. J. Clin. Endocrinol. Metab. 76:895-901. 